\title{
Intrapersonal and interpersonal dimensions of cancer perception: a confirmatory factor analysis of the cancer experience and efficacy scale (CEES)
}

\author{
Wai Kai Hou
}

Received: 2 March 2009 / Accepted: 21 June 2009 / Published online: 9 July 2009

(C) Springer-Verlag 2009

\begin{abstract}
Purpose Sociocultural factors influence psychological adjustment to cancer in Asian patients in two major ways: prioritization of relationships over individual orientations and belief in the efficacy of interpersonal cooperation. We derived and validated among Chinese colorectal cancer (CRC) patients an instrument assessing cancer perceptions to enable the study of the sociocultural processes.

Patients and methods Qualitative interviews $(n=16)$ derived 15 items addressing interpersonal experience in Chinese CRC patients' adjustment. These 15 items and 18 corresponding self-referent items were administered to 166 Chinese CRC survivors and subjected to exploratory factor analysis (EFA) to establish the initial scale structure and reliability. The final 29 items, together with other psychometric measures, were administered to a second cohort of 215 CRC patients and subjected to confirmatory factor analysis (CFA).

Results EFA (63.35\% of the total variance) extracted six factors: personal strain, socioeconomic strain, emotional strain, personal efficacy, collective efficacy, and proxy efficacy. CFA confirmed the psychometric structure $\left[\chi^{2}(d f)=702.91\right.$ (368); Comparative Fit Index $=0.95$; Nonnormed Fit Index $=$ 0.94; Incremental Fit Index $=0.95$; standardized root mean square residual $=0.08]$ of the six factors by using a model with
\end{abstract}

W. K. Hou $(\square)$

Department of Community Medicine and School of Public Health,

Li Ka Shing Faculty of Medicine,

The University of Hong Kong,

Pokfulam, Hong Kong

e-mail: houwaikai@gmail.com two latent factors: experience and efficacy. All subscales were reliable $(\alpha=0.76-0.92)$. Appropriate correlations with adjustment outcomes (symptom distress, psychological morbidity, and subjective well-being), optimistic personalities, and social relational quality indicated its convergent and divergent validity. Known group comparisons (i.e., age, active treatment, and colostomy) showed its clinical utility.

Conclusion The cancer experience and efficacy scale is a valid multidimensional instrument for assessing intrapersonal and interpersonal dimensions of cancer experience in Asian patients, potentiating existing patient-reported outcome measures.

Keywords Asians · Colorectal cancer - Interpersonal cancer perceptions · Psychometric evaluations · Sociocultural differences

\section{Introduction}

Psychosocial adjustment in Asian cancer patients is different from non-Asian patients due to distinctly different sociocultural backgrounds. Asian cultures prioritize relationships over individual orientations, particularly when dealing with stressful events. Cross-cultural studies have consistently found that in coping with stress, although social support has similar benefits for Asian and European Americans, the former weight more heavily the maintenance of interpersonal emotional well-being and relational harmony over seeking support for personal problems [21, 41]. Second, Asians hold a strong belief in interdependence among close social partners and place less emphasis on Western cultural imperatives of personal agency and accomplishment [10]. While perceived personal control is associated with psychological well-being among Americans in the face of job 
demands, confidence in interpersonal cooperation is associated with less psychosomatic and depressive symptoms among Chinese [34]. Interpersonal dimensions of adjustment to cancer, in addition to the intrapersonal dimensions, should be considered when investigating Asian populations.

Perceptions of the interpersonal relations among close social partners have been shown to be important in adapting to the diagnosis and treatment of cancer in Asian patients. Hong Kong Chinese colorectal cancer (CRC) patients reporting emotional coexperience and a secure alliance with family and friends also foresee continuous support from these people and demonstrate coping confidence and better psychological functioning $[15,16]$. While Caucasian breast cancer patients emphasize participation in peer support groups during treatment, Asian patients highlight the importance of a cooperative feeling and love in their interactions with family and friends [2]. Chinese and Japanese women with breast cancer tend to perceive similar levels of support and express lower demand for additional support than do their Caucasian counterparts despite having smaller social networks [20]. If interpersonal and intrapersonal dimensions of interaction have an equivalent impact on adjustment in Asian patients, a valid and reliable patientreported instrument for capturing both is needed. The utility of such instrument also extends beyond geographical Asia as substantial Asian communities exist in most countries and often retain their social values over generations.

The relationship between perceptions of a stressful event and physical and psychosocial adjustment has been highlighted in Lazarus' transactional model of coping [24]. The model asserts that a situation is appraised as "stressful" and undermines physical and mental health only if an individual perceives the situation as incurring a significant negative impact and not to be effectively managed by coping efforts. A generic perception of negative impact predicts psychological morbidity in the year after diagnosis [26], while interference in daily and social life is associated with impairments to the quality of life (QoL) among mediumand long-term survivors [1, 45]. Personal control over cancer course [6, 31], physical symptoms, and emotion regulation $[28,42]$ has also been found to be related concurrently and prospectively with psychological distress and well-being. However, only one study has assessed interpersonal dimensions, namely familial distress and strained relationship, among older long-term survivors by using a validated instrument (i.e., impact of cancer scale) [45].

This study aims to develop a psychometric instrument for assessing perceptions of both intrapersonal and interpersonal dimensions of cancer experience and tests this in Asian cancer patients. I decided to validate the instrument among samples of Chinese CRC patients because increasing incidence in the past decades suggests a need to understand correlates of adjustment so as to optimize clinical and psychosocial services among this population. As the People's Republic of China (PRC) modernizes, CRC demonstrates the sharpest increases in incidence, becoming the third commonest cancer in urban Shanghai [19] and the fastest increasing cancer in Qidong city [4]. In Hong Kong, the most developed city in the PRC, CRC ranks the second in incidence and mortality [14]. CRC is also the most frequent cancer among Chinese Singaporeans [35]. However, only few studies have examined psychosocial adjustment in Chinese CRC populations [15-17].

\section{Patients and methods}

As part of a larger longitudinal study on Hong Kong Chinese people with CRC, I used a three-stage process to identify salient interpersonal experience in these people. Stage 1 involved a qualitative interview of CRC patients to help identify appropriate item domains. Two studies detailed in this paper followed: study 1 established the psychometric structure and reliability of the instrument; study 2 administered the instrument to a separate cohort of CRC patients to assess scale psychometrics. Upon obtaining the Ethics Committees' approvals, suitable people were identified and recruited at Queen Elizabeth Hospital (QEH), the largest Hong Kong governmentfunded clinical oncology unit and community settings.

\section{Item development}

A qualitative study [15] captured the mechanisms through which psychosocial resources and coping procedures impact upon adjustment. Chinese CRC patients were recruited and interviewed in QEH between March and July 2005; data saturation (i.e., no new data over three consecutive interviews) was achieved with 16 participants. Participants ranged in age from 34 to 73 years (six females, ten males); most $(n=14)$ were married; one was widowed and one single. These people had stages II to IV colon $(n=11)$ or rectal cancer $(n=5)$; all had received curative/palliative surgery and radiotherapy and/or chemotherapy, with seven having temporary/permanent stoma.

Based on the qualitative findings, 15 items were written in Chinese to address significant interpersonal experience: difficulties experienced by family and friends $(n=5)$, family financial strain $(n=2)$, efficacy in managing cancer with family and friends $(n=5)$ and with medical professionals $(n=3)$ [15]. I also adapted subscales in the Chinese Illness Perception Questionnaire-Revised (http://www.uib. no/ipq) [29] to address comparable self-referent dimensions (consequences, $n=6$; emotional representations, $n=6$; personal control, $n=6$ ). The instruction read "We are interested to know your personal views regarding colon/rectal cancer. Please indicate how much you agree or disagree with the following statements." Participants rated each item on a 
five-point scale $(1=$ strongly disagree, $2=$ disagree, $3=$ uncertain, $4=$ agree, $5=$ strongly agree).

Study 1: Instrument development and piloting

The materials were translated into English by a trained bilingual translator, then back-translated into Chinese by a naïve second translator. The two translators were Cantonese-speaking Chinese with university degrees in Chinese-English translation. The author examined semantic and conceptual equivalence of the original and the backtranslated versions. Discrepancies in the two versions were resolved by joint meetings between translators and when necessary by reiteration of the translation process.

The draft instrument (hereafter referred to as Cancer Experience and Efficacy Scale [CEES]) was administered to a convenience cohort of 166 Chinese CRC patients who had completed treatment, recruited opportunistically from two community support centers and QEH over a 3-month period. Participants either completed the draft instrument independently or by means of telephone or face-to-face interview by the author. Demographic and medical data were obtained from medical records. After completing the instrument, all participants were debriefed individually or in groups to identify any problems or ambiguities in the items.

\section{Study 2: Validation}

The CEES was then administered via structured telephone interview to a second cohort of 215 Chinese CRC patients recruited from QEH. Inclusion criteria were 21 years of age or older, histological diagnosis of CRC within 12 weeks, and no prior malignancies. Exclusion criteria were active axis 1 psychiatric disorders, linguistic/intellectual difficulties, brain metastasis, or serious medical condition(s). A standardized pro forma was used to obtain demographic information; a Chart Review Data Sheet recorded medical information from hospital charts. Participants also completed the following measures (Table 4).

Physical functioning A self-developed checklist assesses nine general and CRC-specific symptoms: stomachache, gas/bloating, belch, proctalgia, sleep problems, fatigue, pain, nausea, and loss of appetite [15, 23], with a four-point scale to indicate presence and severity: $0=$ not at all, $1=$ a little bit, 2 = quite $a$ bit, and 3 = very much. Cronbach's alpha $(\alpha)$ for the current administration was 0.78. Subjective health status was assessed as $1=$ very poor, $2=$ poor, $3=$ so far so good, and $4=$ very good.

Psychological morbidity Anxiety and depression were measured using Chinese Hospital Anxiety and Depression Scale (HADS), which uses a four-point scale (e.g., $0=n o t$ at all, $1=$ not very much, $2=$ quite a lot, $3=$ very much indeed) [25]. Seven items measure anxiety (HADS-A) and depressive symptoms (HADS-D), respectively. The Chinese HADS was shown to be reliable $(\alpha>0.70)$ and valid among Chinese [17]. Alphas for the HADS-A and HADS-D were 0.89 and 0.87 , respectively.

Psychological well-being The ten-item subscale of Chinese Affect Scale (CAS-PA) [11] assesses frequency of positive affect in the past two weeks on a five-point scale: $0=$ not at all, $1=$ rarely, $2=$ sometimes, $3=$ often, and $4=$ all the time. The CAS-PA demonstrates $\alpha>0.85$ in Chinese young and middle-aged adults [11] and $\alpha=0.92$ in the current administration. The Satisfaction with Life Scale (SWLS) [5] measured participants' current sense of fulfillment by using a four-point scale from strongly disagree (1) through strongly agree (4). The SWLS generates $\alpha>0.80$ across various studies [32], including this study $(0.88)$.

Optimistic personalities The Chinese Revised Life Orientation Test (C-LOT-R) [22] assesses positive outcome expectancies. The C-LOT-R has demonstrated satisfactory reliability $(\alpha=0.61-0.71)$ and validity in Chinese populations [22]. The eight-item Chinese Hope Scale (HS) [18] assesses the bifacet dispositional hope of Snyder et al. [38] and has been demonstrated to be reliable $(\alpha=0.70-0.90)$. Participants rate each item on a four-point scale $(1=$ strongly disagree, $4=$ strongly agree). Alphas for C-LOT-R and HS were 0.76 and 0.84 respectively.

Social relationships Validated for use in Chinese CRC patients [16], the Social Relational Quality Scale (SRQS) measures three qualitative aspects of social relationships, family intimacy $(\alpha=0.78)$, family commitment $(\alpha=0.78)$, and friendships $(\alpha=0.84)$, on a four-point scale $(1=$ strongly disagree, $4=$ strongly agree).

\section{Data analysis}

Following data cleaning and checking, missing values were excluded pairwise. Item-to-total correlations $(r>0.30)$ and unrotated factor extraction demonstrated item-construct loadings [37]. Unless otherwise specified, all analyses were performed using SPSS software (v.14, SPSS Inc., Chicago, IL, USA).

Exploratory factor analysis (EFA) with promax rotation was conducted on the CEES draft in study 1 . Factorability of the item correlation matrix was tested by using the Kaiser-Meyer-Olkin (KMO) index and Bartlett's test of sphericity [40]. The optimal number of factors was determined by sequentially using latent root criteria (eigenvalues $>1.0$ ) and scree plot. Item loadings should exceed 0.40 . Factor reliability was determined using three 
methods: $\alpha \geq 0.70$, interitem correlations $\geq 0.30$, and item-tototal correlations $\geq 0.50[40]$.

Based on the EFA results, confirmatory factor analysis (CFA) was performed with LISREL 8.54 (Scientific Software International Inc., Lincolnwood, IL, USA) on the CEES in study 2. The Comparative Fit Index (CFI), Nonnormed Fit Index (NNFI), Incremental Fit Index (IFI), and standardized root mean square residual (SRMR) were used to evaluate data model fit [8]. The model was accepted if all fit indices $>0.95$ and the SRMR $<0.08$; correlations between error covariances of items were added to the model based on modification indices (MI) and expected parameter change statistics (EPC) [8].

Correlational analysis evaluated the psychometrics of the CEES relative to the other measures. Lower perceived negative impact $[1,26]$ and higher personal control $[6,28,31,42]$ are associated with less distress and higher subjective well-being among cancer patients. If the CEES assesses dimensions significant to adjustment, subscales measuring negative experience should be positively correlated with distress and inversely correlated with well-being, whereas subscales measuring coping efficacy should be inversely correlated with distress and positively correlated with well-being. To determine appropriate convergence and divergence, correlations between CEES subscales and psychosocial measures were examined. Optimistic personalities and good social relationships enhance coping efficacy in stressful situations [3] and are therefore predicted to be positively correlated with CEES efficacy subscales. I also analyzed correlations between subscales assessing negative experience and optimistic personalities and social relational quality, assuming that perception of negative cancer experience is time specific and thus weakly correlated with these psychosocial resources, which are developed over an extended period of time.

Known group comparisons were performed by using Mann-Whitney $U$ tests $(p<0.05)$. Younger age $(<65$ years $)$ [30], active adjuvant therapies [36, 43], and colostomy [33] significantly predict psychological morbidity among CRC patients. I anticipated that participants who were younger $(<$ median 67 years) [27], receiving adjuvant therapies, or wearing a stoma at survey reported higher scores on negative experience and lower scores on efficacy.

\section{Results}

\section{Study 1}

\section{Participants}

Of 206 potential participants identified and approached via the Hong Kong Stoma Association (site $1 ; n=107$ ), a NGO Support and Resource Center (Site 2; $n=86$ ), and QEH ( $n=$ 13), $166(81 \%)$ participated in study 1: 83 from site 1,70 from site 2, and 13 from QEH (Table 1). Age, sex ratio, and time since diagnosis did not differentiate participants $(n=$ 166) from nonparticipants $(n=40)$. Bonferroni-adjusted comparisons showed a significant difference in the distribution of tumor site between sites 1 and $2(p<0.0001)$. Demographic and medical characteristics of the participants are summarized in Table 1.

Sixty-four percent of participants completed the questionnaires, while $23 \%$ completed telephone and $13 \%$ face-to-face interviews. There were more rectal cancer patients $[t(164)=-1.14 ; p<0.05]$ and longer time since diagnosis $[t(164)=0.82 ; p<0.05]$ among self-completing participants.

\section{Debriefing and item analysis}

Participants considered the item "My colon/rectal cancer has serious financial consequences" ambiguous and a duplicate of items 9 and 10 (Table 2). The item "My colon/rectal cancer strongly affects the way others see me" was irrelevant because participants believed that people cannot tell the illness from their appearance. Participants also expressed difficulty in answering to the item "My colon/rectal cancer is a serious condition" because they believed that only doctors know their conditions. Lastly, most participants agreed strongly with the reverse-worded item "My actions will have no affect on the outcome of my colon/rectal cancer" irrespective of their scores on the other personal control items [29], reflecting a generalized fatalism over life events [10]. These four items also displayed extremely low item-tototal correlations and did not load onto the first unrotated factor, suggesting that they were not tapping the same construct and thus were dropped.

\section{Factor structure}

Rotated factor analysis was performed on the 29 remaining items (Table 2). The KMO index (0.83) and Bartlett's test $\left(\chi^{2}=2,337.66, d f=406, p<0.0001\right)$ indicated that the sample size was adequate and the extracted factors accounted for substantial observed variance. Communality values (range $=0.33-0.76$ ) suggested that a satisfactory-tolarge proportion of item variance was predicted by the underlying factors. The latent root criterion suggested a sixfactor model $(63.35 \%$ of the total observed variance); inspection of the scree plot showed a noticeable difference in slope after the first six eigenvalues. Orthogonal (varimax) rotation generated comparable results.

Factor 1 (socioeconomic strain; 26.57\% of observed variance) included items addressing difficulties and distress experienced by family and friends and the expected financial difficulties on family. Factor 2 (emotional strain, $12.39 \%$ of observed variance) included items addressing participants' cancer-specific emotional distress. Factor 3 
Table 1 Participant characteristics

Study $1(n=166)$

Study $2(n=215)$

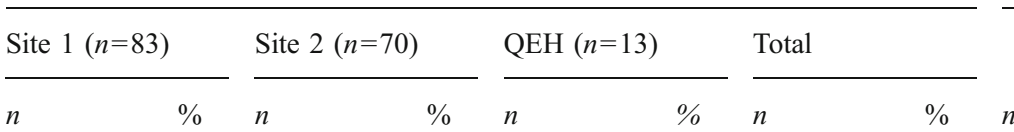

Demographic characteristic

Mean age in years (SD)

$61.55(9.38)$

$60.93(9.04)$

$55.85(8.14)$

$60.84(9.22)$

$64.28(10.58)$

Sex

Female

Male

Marital status

Single

Married

Divorced/widowed

Education level

No formal

Elementary

Secondary

Tertiary

Household income (HK\$)

$<\$ 5,000$

$\$ 5,001-\$ 10,000$

$\$ 10,001-\$ 20,000$

$\$ 20,001-\$ 30,000$

$>\$ 30,000$

Employment

Employed

Retired

Housewife

Unemployed

Medical characteristic

Tumor site

Colon
Rectum
Stage
Unknown
I
II
III
IV

Mean time since Dx in days (SD)

Year(s) since Dx

$$
\begin{aligned}
& 0-2 \\
& 3-5 \\
& \geq 5
\end{aligned}
$$

Surgical extent

No surgery

Open

Laparoscopic

Adjuvant therapies

Radiation therapy (RT)

\section{4}

49

3

67

13

\section{8}

32

36

7

14

24

27

12

4

18

37

16

12

16

67

16

13

23

27

4

47

9

27

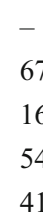

67

16

54

41 $\begin{array}{ll}41.0 & 37\end{array}$

$59.0 \quad 33$

3.63

$80.7 \quad 55$

$15.7 \quad 12$

$9.6 \quad 3$

$38.6 \quad 29$

$43.4 \quad 31$

8.47

$\begin{array}{ll}17.3 & 12\end{array}$

$29.6 \quad 25$

$33.3 \quad 13$

14.89

$4.9 \quad 5$

$21.7 \quad 11$

$44.6 \quad 35$

19.321

14.53

$19.3 \quad 41$

$80.7 \quad 29$

$19.3 \quad 6$

$15.7 \quad 4$

$27.7 \quad 13$

$32.5 \quad 39$

$4.8 \quad 8$

$56.6 \quad 54$

$10.8 \quad 11$

$32.5 \quad 15$

$\begin{array}{ll}- & - \\ 80.7 & 62\end{array}$

19.38

$65.1 \quad 57$

$49.4 \quad 19$
$52.9 \quad 6$

47.17

$4.3 \quad 1$

78.69

17.13

$4.3-$

$41.4 \quad 8$

$44.3 \quad 4$

$10.0 \quad 1$

$18.8 \quad 1$

39.16

20.32

14.12

$7.9 \quad 2$

$15.7 \quad 3$

$50.0 \quad 7$

$30.0 \quad 2$

$4.3 \quad 1$

$58.6 \quad 5$

$41.4 \quad 8$

$8.6-$

$5.7 \quad-$

$18.6 \quad 1$

\begin{tabular}{ll}
$55.7 \quad 8$ \\
\hline
\end{tabular}

$11.4 \quad 4$

$62.8 \quad 12$

$15.7 \quad 1$

21.4 -

$\begin{array}{ll}- & - \\ 88.6 & 11\end{array}$

$11.4 \quad 2$

$81.4 \quad 12$

27.17
$46.2 \quad 77$

$53.8 \quad 89$

$7.7 \quad 7$
69

69.2131

$23.1 \quad 28$

- 11

$61.5 \quad 69$

$30.8 \quad 71$

$7.7 \quad 15$

$\begin{array}{ll}7.7 & 27\end{array}$

$46.2 \quad 55$

$15.4 \quad 42$

$15.4 \quad 23$

$15.4 \quad 11$

$23.1 \quad 32$

$53.8 \quad 79$

$15.4 \quad 39$

$7.7 \quad 16$

$38.5 \quad 62$

$61.5 \quad 104$

- 23

$-\quad 17$
$-\quad 36$

$7.7 \quad 36$

$61.5 \quad 74$

$30.8 \quad 16$

$92.3 \quad 103$

$7.7 \quad 21$

- 42

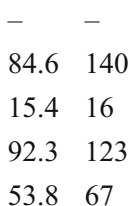

$46.4 \quad 82$

$53.6 \quad 133$

$4.2 \quad 14$

$78.9 \quad 168$

$16.9 \quad 33$

\begin{tabular}{ll}
$6.6 \quad 53$ \\
\hline
\end{tabular}

$41.6 \quad 70$

$42.8 \quad 76$

$9.0 \quad 16$

$17.1 \quad 52$

$34.8 \quad 62$

$26.6 \quad 64$

$14.6 \quad 24$

$\begin{array}{ll}7 & 13\end{array}$

$19.3 \quad 37$

$47.6 \quad 100$

$23.5 \quad 43$

$9.6 \quad 35$

$37.3 \quad 113$

$62.7 \quad 102$

$13.9-$

10.25

$21.7 \quad 46$

$44.6 \quad 124$

$9.6 \quad 40$

126.11 (18.70)

62.1

12.7

25.3

$\begin{array}{lll}- & 27 & 12.6 \\ 84.3 & 144 & 67.0 \\ 15.7 & 44 & 20.5 \\ 74.1 & 131 & 60.9 \\ 40.4 & 20 & 9.3\end{array}$

52.6

47.4

38.0

62.0

6.5

78.1

15.4

24.5

32.6

35.3

7.4

24.2

28.8

29.8

11.2

6.0

17.2

46.5

20.0

16.3

21.4

57.7

18.6

9.3 
Table 1 (continued)

\begin{tabular}{|c|c|c|c|c|c|c|c|c|c|c|}
\hline & \multicolumn{8}{|c|}{ Study $1(n=166)$} & \multicolumn{2}{|c|}{ Study $2(n=215)$} \\
\hline & \multicolumn{2}{|c|}{ Site $1(n=83)$} & \multicolumn{2}{|c|}{ Site $2(n=70)$} & \multicolumn{2}{|c|}{ QEH $(n=13)$} & \multicolumn{2}{|c|}{ Total } & \multirow[b]{2}{*}{$n$} & \multirow[b]{2}{*}{$\%$} \\
\hline & $n$ & $\%$ & $n$ & $\%$ & $n$ & $\%$ & $n$ & $\%$ & & \\
\hline Chemotherapy (Chemo) & 49 & 59.0 & 56 & 80.0 & 11 & 84.6 & 116 & 69.9 & 110 & 51.2 \\
\hline RT + Chemo & - & - & - & - & - & - & - & - & 1 & 0.5 \\
\hline Colostomy at survey & 72 & 86.7 & 1 & 1.4 & 77 & 77 & 77 & 46.4 & 61 & 28.4 \\
\hline
\end{tabular}

$\mathrm{US} \$ 1=\mathrm{HK} \$ 7.8$

$S D$ standard deviation, Dx diagnosis, Site 1 Hong Kong Stoma Association, Site 2 NGO Support and Resource Center, $Q E H$ Queen Elizabeth Hospital

(personal efficacy, $7.51 \%$ of observed variance) included items addressing personal efficacy in coping with the illness. Factor 4 (personal strain, 6.61\% of observed variance) included items addressing negative impact of the illness on participants' daily living. Factor 5 (collective efficacy, 5.32\% of observed variance) included items addressing coping efficacy through collaborating with family or friends. Factor 6 (proxy efficacy, 4.95\% of observed variance) included items addressing coping efficacy through working with medical professionals.

\section{Internal consistency}

Alpha for Factor 1, 2, 3, 4, 5, and 6 were 0.89, 0.89, 0.76, $0.85,0.75$, and 0.83 respectively, while the mean interitem correlations were $0.57,0.58,0.39,0.58,0.33$, and 0.42 , respectively (Table 3 ). All item-to-total correlations exceeded or approached 0.50 (range $=0.44-0.79)$.

\section{Study 2}

\section{Participants}

Of 305 eligible Hong Kong Chinese CRC patients attending the new-case clinics in QEH between July 2006 and March 2007, 263 (86\%) were approached for participation, among which $234(89 \%)$ were recruited within 12 weeks of histological diagnosis $($ mean $=36$ days, $\mathrm{SD}=18.70)$. Three months after giving fully informed consent, 215 participants were administered the CEES together with other measures via structured telephone interview. None of the demographic and medical characteristics differentiated the participants $(n=215)$ from the dropouts $(n=19)$. Characteristics of the participants are summarized in Table 1.

\section{Factor structure}

The six factors identified in study 1 were entered into two latent factors in a CFA model: experience and efficacy
(Fig. 1). Correlations of error covariances between items 9 and 10 (expected financial strains) and between items 18 and 19 (personal efficacy) were added to the model due to large MI and EPC. All fit indices and SRMR approached or exceeded cutoff criteria, indicating good data model fit $\left[\chi^{2}(d f)=702.91(368) ; \mathrm{CFI}=0.95 ; \mathrm{NNFI}=0.94 ; \mathrm{IFI}=\right.$ 0.95 ; $\mathrm{SRMR}=0.08]$. All subscales were internally consistent $(\alpha=0.79-0.92$; Table 4$)$.

\section{Concurrent validity}

Correlations between CEES subscales and outcome variables indicated conceptual consistency between CEES and adjustment (Table 4). Physical symptom severity and psychological distress (HADS-A and HAD-D) were positively correlated with all experience subscales $(r=0.28-0.65)$ and inversely correlated with personal and collective efficacy subscales ( $r=-0.52$ to -0.24$)$. Subjective health was inversely correlated with experience subscales $(r=-0.42$ to -0.31$)$ and positively correlated with personal and collective efficacy $(r=0.40 ; 0.24)$. Psychological well-being (CASPA and SWLS) was correlated with all subscales in predicted directions ( $r=-0.56$ to 0.50 ).

\section{Convergent and divergent validity}

Correlations of CEES scores with optimistic personalities (C-LOT-R and HS) and SRQS scores confirmed appropriate convergence and divergence (Table 4). Scores on optimistic personalities were uncorrelated or weakly correlated with experience subscales $(r \leq-0.22)$ but were positively correlated with personal efficacy $(r=0.26-$ $0.30)$ and collective efficacy $(r=0.28-0.43)$, except for the correlation with emotional strain $(r=-0.33)$. SRQS subscale scores were uncorrelated with experience subscales but were moderately correlated with collective efficacy $(r=0.33-0.50)$; a modest correlation was observed between SRQS friendships and CEES personal efficacy $(r=0.22)$. 
Table 2 Exploratory factor analysis of the CEES (promax rotation)

Socioeconomic strain

5 My colon/rectal cancer causes much trouble in my close social partners' (e.g., family, friends) life

$6 \mathrm{My}$ colon/rectal cancer makes me a burden for the life of my close social partners (e.g., family, friends)

7 My colon/rectal cancer makes me unable to take care of my family and provide them with what they need

9 My colon/rectal cancer makes my family and I experience actual hardships such as inadequate housing, food, or medical attention in the next few months

10 My colon/rectal cancer makes my family and I reduce our standard of living to the bare necessities of life in the next few months

8 My colon/rectal cancer hurts the feeling of those who are close to me (e.g., family, friends)

Emotional strain

13 My colon/rectal cancer makes me feel angry

11 I get depressed when I think about my colon/rectal cancer

16 My colon/rectal cancer makes me feel afraid

12 When I think about my colon/rectal cancer I get upset

15 Having colon/rectal cancer makes me feel anxious

$14 \mathrm{My}$ colon/rectal cancer does not worry $\mathrm{me}^{\mathrm{a}}$

Personal efficacy

18 What I do can determine whether my colon/rectal cancer gets better or worse

19 The course of my colon/rectal cancer depends on me

$\begin{array}{ccccccc}0.88 & -0.07 & 0.03 & -0.04 & 0.14 & -0.09 & 0.74 \\ 0.78 & -0.02 & 0.01 & 0.08 & 0.09 & 0.05 & 0.74 \\ 0.77 & -0.09 & 0.00 & 0.15 & 0.02 & 0.04 & 0.76 \\ 0.76 & 0.10 & 0.10 & -0.10 & -0.18 & 0.02 & 0.70 \\ 0.68 & 0.05 & 0.05 & -0.05 & -0.13 & 0.05 & 0.65 \\ 0.55 & 0.10 & -0.20 & 0.10 & 0.10 & -0.09 & 0.64\end{array}$

17 There is a lot which I can do to control the symptoms of my colon/rectal cancer

$\begin{array}{rrrrrrr}-0.07 & 0.79 & -0.02 & 0.09 & 0.00 & 0.07 & 0.73 \\ 0.13 & 0.77 & 0.10 & 0.00 & -0.05 & -0.07 & 0.79 \\ -0.06 & 0.76 & -0.02 & 0.01 & 0.05 & -0.02 & 0.70 \\ 0.15 & 0.74 & 0.08 & -0.04 & -0.10 & -0.01 & 0.75 \\ 0.10 & 0.68 & 0.03 & 0.06 & 0.13 & -0.02 & 0.70 \\ 0.15 & -0.68 & 0.02 & -0.15 & -0.01 & 0.01 & 0.59\end{array}$

20 I have the power to influence my colon/rectal cancer

21 What I do can determine whether the symptoms of my colon/rectal cancer get better or worse

Personal strain

4 My colon/rectal cancer causes much inconvenience to daily life

2 My colon/rectal cancer does not affect my life much ${ }^{\mathrm{a}}$

1 My colon/rectal cancer has major consequences on my life

3 My colon/rectal cancer strongly affects my daily routine

Collective efficacy

24 Working together with my family and friends, I can solve many of the problems arising from my colon/rectal cancer

22 By joining with family and friends, I have a great deal of control over the problems arising from my colon/rectal cancer

23 The course of my colon/rectal cancer in the future mostly depends on my being helped and supported by family and friends/colleagues

25 My family are able to manage well with any problems I might have from my colon/rectal cancer for me

26 My friends/coworkers are able to overcome any problems I might have from my colon/rectal cancer for me

Proxy efficacy

29 Doctors are able to solve any problems resulting from my colon/rectal cancer for me

28 By collaborating with my doctors/medical professionals, we can have more control over my colon/rectal cancer

27 With the help of my doctors/medical professionals, I have more control over my colon/rectal cancer

$\begin{array}{rrrrrrr}0.03 & 0.01 & 0.78 & 0.03 & -0.03 & 0.03 & 0.65 \\ -0.11 & 0.04 & 0.72 & 0.01 & -0.04 & 0.07 & 0.61 \\ -0.06 & 0.05 & 0.58 & 0.12 & 0.05 & 0.14 & 0.51 \\ 0.04 & 0.13 & 0.55 & -0.07 & 0.01 & -0.16 & 0.46 \\ 0.21 & -0.12 & 0.54 & -0.17 & 0.05 & -0.07 & 0.46\end{array}$

$\begin{array}{lllllll}0.22 & 0.01 & -0.07 & 0.71 & -0.00 & 0.05 & 0.78\end{array}$

$\begin{array}{lllllll}0.09 & -0.13 & -0.07 & -0.67 & 0.14 & 0.04 & 0.62\end{array}$

$\begin{array}{lllllll}-0.01 & 0.13 & -0.06 & 0.66 & 0.12 & -0.09 & 0.61\end{array}$

$\begin{array}{lllllll}0.29 & -0.01 & -0.01 & 0.62 & -0.08 & 0.07 & 0.74\end{array}$

$\begin{array}{lllllll}0.03 & -0.13 & -0.03 & 0.11 & 0.68 & 0.06 & 0.59\end{array}$

$\begin{array}{lllllll}-0.12 & -0.11 & 0.19 & 0.18 & 0.66 & -0.17 & 0.52\end{array}$

$\begin{array}{lllllll}0.06 & -0.09 & 0.13 & -0.14 & 0.62 & -0.01 & 0.58\end{array}$

$\begin{array}{lllllll}0.05 & 0.22 & -0.17 & -0.13 & 0.61 & 0.13 & 0.47\end{array}$

$\begin{array}{lllllll}0.02 & 0.29 & -0.03 & -0.26 & 0.46 & 0.08 & 0.44\end{array}$

$\begin{array}{lllllll}0.06 & -0.10 & -0.04 & -0.08 & -0.03 & 0.71 & 0.53\end{array}$

$\begin{array}{lllllll}-0.03 & 0.08 & -0.05 & -0.03 & 0.04 & 0.70 & 0.54\end{array}$

$\begin{array}{lllllll}-0.04 & -0.04 & 0.19 & 0.10 & 0.15 & 0.51 & 0.47\end{array}$

$r$ correlation

${ }^{\text {a }}$ Reverse coded 
Table 3 Test of internal consistency and interfactor correlations of the CEES

$r$ correlation

${ }^{*} p<0.001 ; * * p<0.01$
Factor $(\alpha)$

$\begin{array}{lllllll}\begin{array}{l}\text { Mean } \\ \text { interitem } \\ \boldsymbol{r}\end{array} & 1 & 2 & 3 & 4 & 5 & 6 \\ 0.57 & - & 0.54^{*} & -0.15 & 0.60^{*} & -0.10 & -0.02 \\ 0.58 & & - & -0.07 & 0.48^{*} & -0.10 & -0.02 \\ 0.39 & & & - & -0.24^{* *} & 0.29 * & 0.22 * * \\ 0.58 & & & & - & -0.24 * * & -0.08 \\ 0.33 & & & & & - & 0.32 * \\ 0.43 & & & & & & -\end{array}$

\section{Known group comparisons}

Higher personal, socioeconomic, and emotional strain scores were reported by participants who were younger ( $n=96 ; Z=-5.33$ to -2.06 ) or receiving adjuvant therapies $(n=131 ; Z=-3.81$ to -2.49$)$; stoma patients reported higher personal strain $(n=61 ; Z=-3.12)$. Lower scores on collective efficacy were noted among participants receiving adjuvant therapies $(Z=-2.16)$ or wearing a stoma $(Z=-2.25)$.

\section{Discussion}

Based upon the above analyses, I conclude that the CEES addresses intrapersonal and interpersonal dimensions of adjustment in Chinese CRC patients. The three experience subscales measure perceived strain on patients (personal strain; emotional strain) and their significant others (socioeconomic strain); the three efficacy subscales measure perceived coping efficacy on individual basis (personal efficacy) and through collaborating with family and friends (collective efficacy) and with medical professionals (proxy efficacy). Good internal consistency was demonstrated in all CEES subscales $(\alpha \geq$ 0.75 ). Significant correlations with symptom distress, psychological morbidity (HADS), and subjective well-being were consistent with the CEES having good concurrent validity. Appropriate correlations of the CEES subscales with optimistic personalities and relational quality suggested good convergent and divergent validity. Clinical utility was indicated in higher experience and lower efficacy subscale scores reported by participants who were younger ( $<67$ years), receiving adjuvant therapies, or wearing a stoma. This study
Fig. 1 Standardized coefficients for the confirmatory factor analysis of CEES

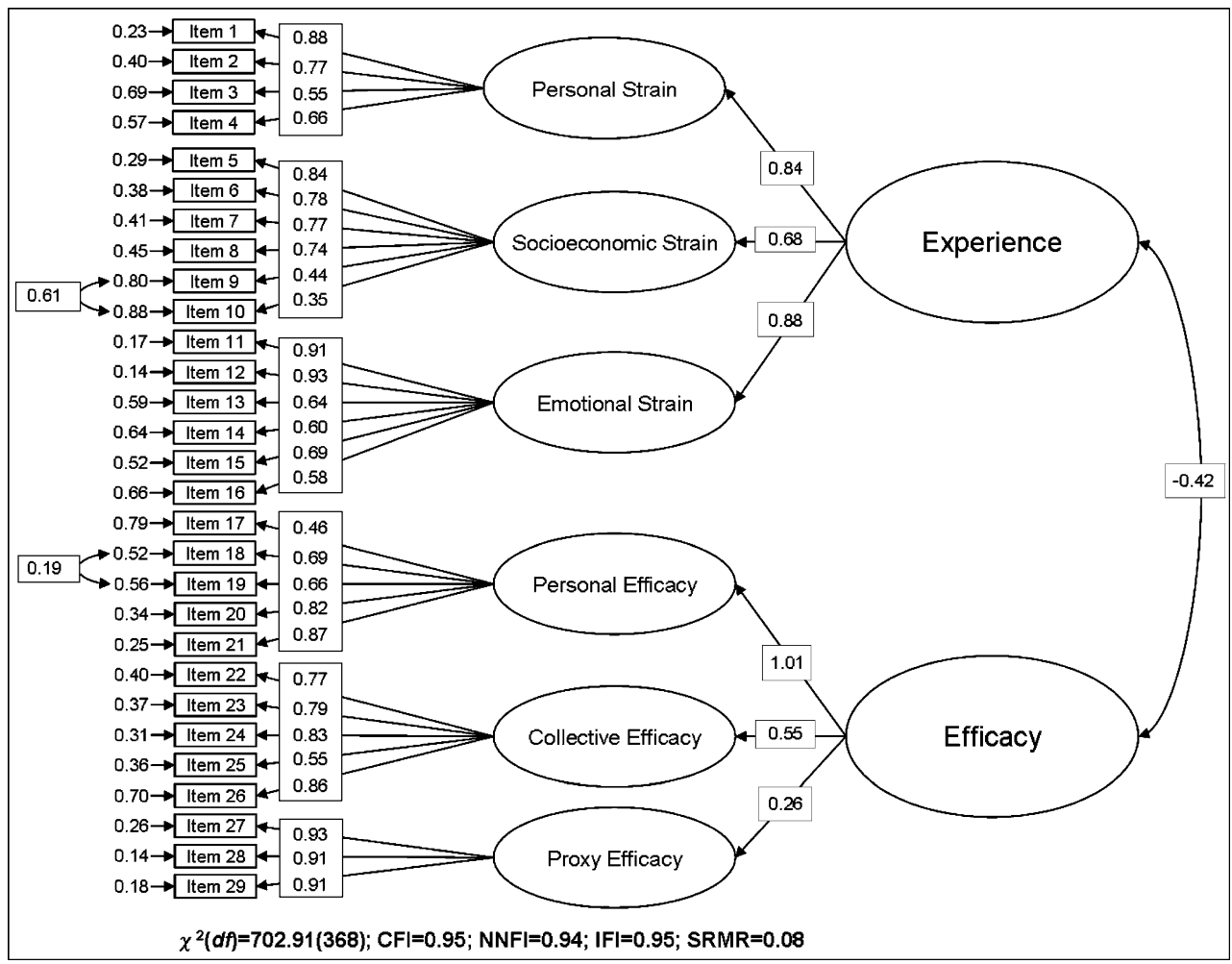


Table 4 Correlation matrix of psychosocial variables with the CEES subscales $(n=215)$

\begin{tabular}{|c|c|c|c|c|c|c|c|c|}
\hline \multirow[b]{2}{*}{ Variable (range) } & \multirow[b]{2}{*}{$\alpha$} & \multirow[b]{2}{*}{ Mean (SD) } & \multicolumn{3}{|c|}{ CEES-experience } & \multicolumn{3}{|c|}{ CEES - efficacy } \\
\hline & & & $\begin{array}{l}\text { Personal } \\
\text { strain }\end{array}$ & $\begin{array}{l}\text { Socioeconomic } \\
\text { strain }\end{array}$ & $\begin{array}{l}\text { Emotional } \\
\text { strain }\end{array}$ & $\begin{array}{l}\text { Personal } \\
\text { efficacy }\end{array}$ & $\begin{array}{l}\text { Collective } \\
\text { efficacy }\end{array}$ & $\begin{array}{l}\text { Proxy } \\
\text { efficacy }\end{array}$ \\
\hline Physical symptoms (0-27) & 0.87 & $3.84(3.63)$ & $0.28 *$ & $0.35^{*}$ & $0.38^{*}$ & $-0.32 *$ & $-0.24 *$ & -0.07 \\
\hline Anxiety $(0-21)$ & 0.89 & $4.35(4.91)$ & $0.52 *$ & $0.45^{*}$ & $0.62 *$ & $-0.35^{*}$ & $-0.30^{*}$ & -0.05 \\
\hline Depression (0-21) & 0.87 & $5.73(5.19)$ & $0.54 *$ & $0.50 *$ & $0.65^{*}$ & $-0.52 *$ & $-0.44^{*}$ & $-0.20 * *$ \\
\hline Subjective health $(1-4)$ & - & $1.99(0.58)$ & $-0.33^{*}$ & $-0.31^{*}$ & $-0.42 *$ & $0.40^{*}$ & $0.24 *$ & 0.05 \\
\hline Positive affect $(0-40)$ & 0.92 & $21.86(9.54)$ & $-0.45^{*}$ & $-0.44^{*}$ & $-0.56^{*}$ & $0.49^{*}$ & $0.50 *$ & $0.19 * *$ \\
\hline Life satisfaction (5-20) & 0.88 & $13.06(3.72)$ & $-0.50^{*}$ & $-0.44^{*}$ & $-0.47 *$ & $0.39 *$ & $0.44^{*}$ & 0.08 \\
\hline Optimism (0-24) & 0.76 & $16.68(3.27)$ & $-0.22 * *$ & -0.10 & $-0.33^{*}$ & $0.26^{*}$ & $0.28 *$ & 0.02 \\
\hline Hope $(0-32)$ & 0.84 & $23.31(4.52)$ & -0.13 & -0.13 & $-0.20 * *$ & $0.30^{*}$ & $0.43^{*}$ & 0.12 \\
\hline Family Intimacy (7-28) & 0.78 & $22.99(3.63)$ & -0.09 & 0.07 & 0.01 & 0.10 & $0.41 * * *$ & -0.01 \\
\hline Family Commitment (5-20) & 0.78 & $17.29(2.46)$ & -0.07 & 0.07 & -0.11 & 0.13 & $0.50 *$ & 0.10 \\
\hline Friendships (5-20) & 0.84 & $13.58(3.68)$ & -0.03 & 0.05 & -0.04 & $0.22 * *$ & $0.33^{*}$ & 0.04 \\
\hline \multicolumn{9}{|l|}{ CEES } \\
\hline Personal strain (4-20) & 0.79 & $13.26(4.53)$ & - & $0.52 *$ & $0.58^{*}$ & $-0.22 * *$ & $-0.15^{*}$ & 0.11 \\
\hline Socioeconomic strain $(6-30)$ & 0.81 & $15.25(5.95)$ & & - & $0.53 *$ & $-0.28^{*}$ & 0.04 & -0.10 \\
\hline Emotional strain $(6-30)$ & 0.87 & $17.36(6.99)$ & & & - & $-0.35^{*}$ & $-0.16^{* * *}$ & -0.06 \\
\hline Personal efficacy (5-25) & 0.83 & $17.18(4.04)$ & & & & - & $0.47 *$ & $0.19 * *$ \\
\hline Collective efficacy (5-25) & 0.85 & $16.27(5.25)$ & & & & & - & $0.17 * * *$ \\
\hline Proxy efficacy (3-15) & 0.92 & $12.49(2.65)$ & & & & & & - \\
\hline
\end{tabular}

$S D$ standard deviation

${ }^{*} p<0.001 ; * * p<0.01 ; * * * p<0.05$

adds to the current literature by providing a psychometric instrument for assessing both self-referent and interpersonal dimensions of cancer perception among patients with an Asian sociocultural background.

Our findings also suggest differential roles for perceived cancer-related strain and efficacy in psychological adjustment to cancer. Previous studies have shown that cognitive coping strategies like positive reinterpretations and fatalistic thoughts mediate the benefit of dispositional positive thinking [7, 39] and perceived social support [12] on cancer patients; collective as well as personal mastery has been found to predict lower perceived stress and psychological morbidity among East Asians [34] and Native Americans [13], whose populations emphasize interdependence among close social partners. However, none addressed the role of cancer-specific perceptions in the association between psychosocial resources and adaptation. In this study, Chinese CRC patients reporting higher personal and collective efficacy in coping with cancer were more optimistic $[18,22]$ and had better social relational quality [16] and adjustment outcomes, suggesting a mediational role for efficacy beliefs between psychosocial resources and adjustment. Collective efficacy might mediate specifically the positive impact of social relational quality on psychological well-being. In contrast, a signif- icant association of personal and socioeconomic strain with decreased psychological well-being but not with the personality and social relational traits demonstrates that perceived strain impacts upon psychological well-being irrespective of preexisting psychosocial resources.

The weak relationship between proxy efficacy and other psychosocial variables might reveal cultural variations in medical experience. Asian patients regard their relationships with doctors to be social and cast unquestioning trust in them; the assumed social contract is that doctors should provide services in a caring manner [9]. A recent study found that medical professionals' emotional support but not treatmentrelated support predict QoL in Chinese lung and liver cancer patients [44]. CEES proxy efficacy subscale possibly assessed a problem-focused dimension with little relevance to Chinese CRC patients' psychological adjustment.

Limitations and conclusions

A number of methodological points warrant discussion. The focus of CEES was derived from people formerly treated for CRC, many of whom faced rectal cancer. The instrument thus should be most sensitive in this population. Also, the CEES was developed and validated in samples of Chinese CRC patients; in particular, the participants in study 2 were a 
convenience sample of CRC patients from one tertiary clinic $(\mathrm{QEH})$ in Hong Kong, restricting generalizability of the findings to other Chinese or Asian populations. Furthermore, cross-sectional design precludes examination of test-retest reliability of the CEES, while the measures of physical functioning were not formal instruments, so some caution is needed in interpreting the findings.

Notwithstanding these limitations, this study contributes to advancing psycho-oncological research in Chinese populations. Instruments have been validated for assessing physical and psychological symptomatology and QoL in Chinese CRC patients (e.g., [23]). However, very little is known on the psychosocial correlates of adjustment among these people. The CEES could be used to reveal specific adaptation needs of these patients in addition to existing QoL instruments. For example, socioeconomic strain impacts patients' psychological well-being independent of coping resources and thus should be assessed and managed by appropriate counseling services. The findings on collective sense of mastery also inform psychosocial interventions for Chinese cancer populations. Future intervention programs could aim at empowering both patients and their family and friends to actively participate in symptom or treatment self-care management. Such programs could enhance collective mastery of Chinese CRC patients, predictive in turn of more sustained and successful coping and positive adjustment outcomes.

Acknowledgments The author is grateful to Dr. C. C. Law, Department of Clinical Oncology, Queen Elizabeth Hospital, for his generous help in participant recruitment and data collection, and Prof. Geoffrey H. Blowers, Department of Psychology, The University of Hong Kong, for his valuable consultation and comments.

\section{References}

1. Alfano CM, McGregor BA, Kuniyuki A, Reeve BB, Bowen DJ, Smith AW, Baumgartner KB, Bernstein L, Ballard-Barbash R, Malone KE, Ganz PA, McTiernan A (2006) Psychometric evaluation of the brief cancer impact assessment among breast cancer survivors. Oncology 70:190-202

2. Ashing-Giwa KT, Padilla G, Tejero J, Kraemer J, Wright K, Coscarelli A, Clayton S, Williams I, Hills D (2004) Understanding the breast cancer experience of women: a qualitative study of African American, Asian American, Latina and Caucasian cancer survivors. Psycho-Oncol 13:408-428

3. Bandura A (1986) Social foundations of thought and action: a social cognitive theory. Prentice-Hall, Englewood Cliffs

4. Chen JG, Zhu J, Parkin DM, Zhang YH, Lu JH, Zhu YR, Chen TY (2006) Trends in the incidence of cancer in Qidong, China, 1978-2002. Int J Cancer 119:1447-1454

5. Diener E, Emmons RA, Larsen RJ, Griffin S (1985) The satisfaction with life scale. J Pers Assess 49:71-75

6. Ell KO, Mantell JE, Hamovitch MB, Nishimoto RH (1989) Social support, sense of control, and coping among patients with breast, lung, or colorectal cancer. J Psychosoc Oncol 7:63-89
7. Epping-Jordan JE, Compas BE, Osowiecki DM, Oppedisano G, Gerhardt C, Primo K, Krag DN (1999) Psychological adjustment in breast cancer: processes of emotional distress. Health Psychol $18: 315-326$

8. Fan X, Thompson B, Wang L (1999) Effects of sample size, estimation methods, and model specification on structural equation modeling fit indexes. Struct Equ Modeling 6:56-83

9. Fielding R, Wong L, Ko L (1998) Strategies of information disclosure to Chinese cancer patients in an Asian community. Psychooncology 7:240-251

10. Fiske AP, Kitayama S, Markus HR, Nisbett RE (1998) The cultural matrix of social psychology. In: Gilbert DT, Fiske ST, Lindzey G (eds) The handbook of social psychology. McGraw-Hill, New York, pp 915-981

11. Hamid PN, Cheng S-T (1996) The development and validation of an index of emotional disposition and mood state: the Chinese affect scale. Educ Psychol Meas 56:995-1014

12. Helgeson VS, Cohen S (1996) Social support and adjustment to cancer: reconciling descriptive, correlational, and intervention research. Health Psychol 15:135-148

13. Hobfoll SE, Jackson A, Hobfoll I, Pierce CA, Young S (2002) The impact of communal-mastery versus self-mastery on emotional outcomes during stressful conditions: a prospective study of Native American women. Am J Community Psychol 30:853-872

14. Hong Kong Cancer Registry (2005) Cancer statistics 2002. Hong Kong Hospital Authority, Hong Kong

15. Hou WK, Lam WWT, Fielding R (2008) Adaptation process and psychosocial resources of Chinese colorectal cancer patients undergoing adjuvant treatment: a qualitative analysis. PsychoOncol. doi:10.1002/pon.1457

16. Hou WK, Lam WWT, Law CC, Fu YT, Fielding R (2008) Measuring social relational quality in colorectal cancer: the Social Relational Quality Scale (SRQS). Psycho-Oncol. doi:10.1002/ pon. 1500

17. Hou WK, Law CC, Fu YT (2008) Does change in positive affect mediate and/or moderate the impact of symptom distress on psychological adjustment after cancer diagnosis? A prospective analysis. Psychol Health. doi:10.1080/08870440802559375

18. Ip YT (2007) The role of hope in buffering hopelessness and suicidal ideation. Dissertation, The University of Hong Kong

19. Jin F, Devesa SS, Chow WH, Zheng W, Ji BT, Fraumeni JF Jr, Gao YT (1999) Cancer incidence trends in urban shanghai, 1972 1994: an update. Int J Cancer 83:435-440

20. Kagawa-Singer M, Wellisch DK, Durvasula R (1997) Impact of breast cancer on Asian American and Anglo American women. Cult Med Psychiatry 21:449-480

21. Kim HS, Sherman DK, Taylor SE (2008) Culture and social support. Am Psychol 63:518-526

22. Lai JCL, Yue X (2000) Measuring optimism in Hong Kong and mainland Chinese with the revised Life Orientation Test. Pers Individ Differ 28:781-796

23. Law CC, Tak Lam WW, Fu YT, Wong KH, Sprangers MA, Fielding R (2008) Validation of the Chinese version of the EORTC colorectal cancer-specific quality-of-life questionnaire module (QLQ-CR38). J Pain Symptom Manage 35:203-213

24. Lazarus RS (1991) Emotion and adaptation. Oxford University Press, New York

25. Leung CM, Ho S, Kan CS, Hung CH et al (1993) Evaluation of the Chinese version of the Hospital Anxiety and Depression Scale. A cross-cultural perspective. Int J Psychosom 40:29-34

26. Lynch BM, Steginga SK, Hawkes AL, Pakenham KI, Dunn J (2008) Describing and predicting psychological distress after colorectal cancer. Cancer 112:1363-1370

27. MacCallum RC, Zhang S, Preacher KJ, Rucker DD (2002) On the practice of dichotomization of quantitative variables. Psychol Methods 7:19-40 
28. Manne SL, Ostroff JS, Norton TR, Fox K, Grana G, Goldstein L (2006) Cancer-specific self-efficacy and psychosocial and functional adaptation to early stage breast cancer. Ann Behav Med $31: 145-154$

29. Moss-Morris R, Weinman J, Petrie KJ, Horne R, Cameron LD, Buick D (2002) The revised illness perception questionnaire (IPQR). Psychol Health 17:1-16

30. Nishigaki M, Oya M, Ueno M, Arai M, Yamaguchi T, Muto T, Kazuma K (2007) The influence of life stage on psychosocial adjustment in colorectal cancer patients. J Psychosoc Oncol 25:71-87

31. Osowiecki D, Compas BE (1998) Psychological adjustment to cancer: control beliefs and coping in adult cancer patients. Cogn Ther Res 22:483-499

32. Pavot W, Diener E (1993) Review of the satisfaction with life scale. Psychol Assess 5:164-172

33. Ross L, Abild-Nielsen AG, Thomsen BL, Karlsen RV, Boesen EH, Johansen C (2007) Quality of life of Danish colorectal cancer patients with and without a stoma Support Care Cancer 15:505-513

34. Schaubroeck J, Lam SSK, Xie JL (2000) Collective efficacy versus self-efficacy in coping responses to stressors and control: a cross-cultural study. J Appl Psychol 85:512-525

35. Seow A, Koh WP, Chia KS, Shi LM, Lee HP, Shanmugaratnam K (2004) Trends in cancer incidence in Singapore 1968-2002. Singapore Cancer Registry report number 6. Singapore Cancer Registry, Singapore

36. Sharma A, Sharp DM, Walker LG, Monson JR (2007) Predictors of early postoperative quality of life after elective resection for colorectal cancer. Ann Surg Oncol 14:3435-3442
37. Smith GT, McCarthy DM (1995) Methodological considerations in the refinement of clinical assessment instruments. Psychol Assess 7:300-308

38. Snyder CR, Harris C, Anderson JR, Holleran SA, Irving LM, Sigmon ST, Yoshinobu L, Gibb J, Langelle C, Harney P (1991) The will and the ways: development and validation of an individual-differences measure of hope. J Pers Soc Psychol 60:570-585

39. Stanton AL, Danoff-Burg S, Huggins ME (2002) The first year after breast cancer diagnosis: hope and coping strategies as predictors of adjustment. Psycho-Oncol 11:93-102

40. Tabachnick BG, Fidell LS (2001) Using multivariate statistics. Allyn and Bacon, Boston

41. Taylor SE, Sherman DK, Kim HS, Jarcho J, Takagi K, Dunagan MS (2004) Culture and social support: who seeks it and why? J Pers Soc Psychol 87:354-362

42. Thompson SC, Sobolew-Shubin A, Galbraith ME, Schwankovsky L, Cruzen D (1993) Maintaining perceptions of control: finding perceived control in low-control circumstances. J Pers Soc Psychol 64:293-304

43. Wilson TR, Alexander DJ, Kind P (2006) Measurement of healthrelated quality of life in the early follow-up of colon and rectal cancer. Dis Colon Rectum 49:1692-1702

44. Wong WS, Fielding R (2008) The association between patient satisfaction and quality of life in Chinese lung and liver cancer patients. Med Care 46:293-302

45. Zebrack BJ, Ganz PA, Bernaards CA, Petersen L, Abraham L (2006) Assessing the impact of cancer: development of a new instrument for long-term survivors. Psycho-Oncol 15:407-421 